\title{
Significance of the expression of MRP1 and MRP2 in peripheral blood mononuclear cells of children with intractable epilepsy
}

\author{
XIAOMING LIU, XUAN YUE, SHENGZHI CHEN, JIAO CHEN and RUI LI \\ Department of Neurology, Xuzhou Children's Hospital, Xuzhou, Jiangsu 221002, P.R. China
}

Received July 7, 2015; Accepted August 27, 2015

DOI: $10.3892 /$ etm.2015.2746

\begin{abstract}
Intactable epilepsy (IE) is relatively common in pediatric epilepsy. The resistance mechanism of IE has been previously investigated. Multidrug-resistant associated protein 1 (MRP1) and MRP2 are associated with drug transport. The aim of the present study was to investigate the expression of MRP1 and MRP2 in peripheral blood mononuclear cells of children with IE. Fifty outpatient or inpatient children were included in the study as the experimental group. Additionally, 50 children with epilepsy controlled by anti-epileptic drugs (AEDs) and 50 healthy children without epilepsy, who served as the control group, were included in the present study. Expression of MRP1 and MRP2 in the peripheral blood mononuclear cells of children in all the groups was detected using RT-PCR and western blot analysis. The results showed that the relative expression of MRP1 and MRP2 mRNA in the peripheral blood mononuclear cells of children with IE (MRP1, 0.795 \pm 0.042 ; MRP2, 0.804 \pm 0.023 ) was higher than that in epilepsy controlled by AEDs (MRP1, $0.682 \pm 0.030$; MRP2, $0.675 \pm 0.021)$ and healthy children without epilepsy (MRP1, 0.665 \pm 0.031 ; MRP2, 0.654 \pm 0.029$)$ $(\mathrm{P}<0.01)$. The mean relative expression of MRP1 and MRP2 protein in the peripheral blood mononuclear cells of children with IE (MRP1, 2.027士0.034; MRP2, 1.902 \pm 0.021 ) was higher than that in children with epilepsy controlled

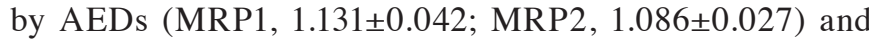
healthy children without epilepsy (MRP1, 1.093 \pm 0.023 ; MRP2, 1.045 \pm 0.018$)(\mathrm{P}<0.01)$. The difference in the MRP1 and MRP2 mRNA and protein expression between the children with epilepsy controlled by AEDs and healthy children without epilepsy was not statistically significant $(\mathrm{P}>0.05)$. In conclusion, a higher expression of MRP1 and MRP2 in the peripheral blood mononuclear cells of children with IE may be relevant to the drug-resistant mechanism of IE.
\end{abstract}

Correspondence to: Rui Li, Department of Neurology, Xuzhou Children's Hospital, 18 Sudibei Road, Xuzhou, Jiangsu 221002, P.R. China

E-mail: xc83668117@163.com

Key words: intractable epilepsy, MRP1, MRP2, peripheral blood mononuclear cells

\section{Introduction}

Intractable epilepsy (IE) accounts for $30-40 \%$ of the pediatric epilepsy and poses a challenge in pediatric neurology (1-2). In recent years, most studies investigating the resistance mechanism of IE have focused on cell death and reconstruction, overexpression of multidrug transporter, and changes of intracephalic drug targets $(3,4)$. Previous studies focused on the association between multidrug transporter and epilepsy tolerance $(5,6,15)$. The multidrug-resistant associated protein (MRP) is an important multidrug transporter, comprising nine MRPs (MRP1-MRP9), which are associated with drug transport. Among these, MRP1 and MRP2 may be related to the drug-resistant mechanisms of IE (7). MRP1 and MRP2 are distributed in the kidneys, liver, lungs, testes and peripheral blood mononuclear cells. They are also expressed in the luminal membrane on the basal side of endothelial cells or the luminal membrane of capillary endothelial cells in the choroid plexus, whose function is to restrict the entry of specific substances into the cerebrospinal fluid $(8,9)$. The aim of the present study was to examine the expression of MRP1 and MRP2 protein in the peripheral blood mononuclear cells of children with IE using RT-PCR and western blot analysis. A higher relative expression of MRP1 and MRP2 mRNA and protein was identified in children with IE compared to the control groups. This higher expression indicates that IE may be relevant to the drug-resistant mechanism of IE.

\section{Materials and methods}

Subjects. For this study, 100 children with epilepsy from the outpatient or inpatient clinic of Xuzhou Children's Hospital (Jiangsu, China) were enrolled between November 2010 and October 2013. The patients were into two groups. The IE group comprised 50 cases, all of which conformed to the criteria formulated by the International League Against Epilepsy (10). The criteria for enrollment were: exact clinical diagnosis, the application of two types of appropriate and tolerable antiepileptic drugs failed to completely avoid epileptic seizure following adequate duration of treatment (duration-free from any epileptic seizure was considered as $\geq 3$ times the longest interictal period prior to treatment or 12 months) and adequate doses of monotherapy or combinatorial treatment, with other nervous system disease history being excluded. Since the longest interictal periods in the enrolled patients was $<3$ months, 
Table I. Expression of mRNA of MRP1 and MRP2 in peripheral blood mononuclear cells of children with intractable epilepsy $($ mean $\pm \mathrm{SD})$.

\begin{tabular}{|c|c|c|c|}
\hline Group & Cases & MRP1 & MRP2 \\
\hline Group of healthy children without epilepsy & 50 & $0.665 \pm 0.031$ & $0.654 \pm 0.029$ \\
\hline Group of children with epilepsy controlled by anti-epileptic drugs & 50 & $0.682 \pm 0.030^{\mathrm{a}}$ & $0.675 \pm 0.021^{\mathrm{a}}$ \\
\hline Group of intractable epilepsy & 50 & $0.795 \pm 0.042^{\mathrm{b}}$ & $0.804 \pm 0.023^{\mathrm{b}}$ \\
\hline F-value & & 121.364 & 292.194 \\
\hline P-value & & $<0.001$ & $<0.001$ \\
\hline
\end{tabular}

${ }^{\mathrm{a}} \mathrm{P}<0.001$ when the group of children with intractable epilepsy was compared to the group of children with epilepsy controlled by anti-epileptic drugs and the group of healthy children without epilepsy. ${ }^{b} \mathrm{P}>0.05$ when the group of children with epilepsy controlled by anti-epileptic drugs was compared to the group of healthy children without epilepsy. MRP, multidrug-resistant associated protein.

12 months was defined as the course of treatment. In the IE group, 29 cases were male and 21 were female, between the ages of 1.2 and 12 years, with an average age of 5.2 \pm 2.1 years, and a course of disease of 1-6 years. Of the 50 cases, 23 were cases of partial seizure, 10 of general tonic-clonic seizure, 3 of myoclonic seizure, 3 of children atypical seizure, 6 of epileptic spasm, and 5 cases of myoclonia atonic seizure.

The epilepsy controlled by anti-epileptic drugs (AEDs) group comprised 50 patients, diagnosed with epilepsy, but who had not experienced a seizure for at least one year following first-line anti-epileptic drug treatment. In this group, 26 cases were male and 24 cases were female, between 1.6 and 10 years of age, with an average age of $4.3 \pm 2.3$ years. Of the 50 cases, 19 were cases of partial seizure, 15 of general tonic-clonic seizure, 5 of myoclonic seizure, 3 of atonic seizure, 3 of myoclonia atonic seizure, 3 of absence seizure and 2 cases of epileptic spasm.

The control group comprised 50 healthy children without epilepsy who served as the control group. In this group, 30 cases were male and 20 cases were female, aged between 2 and 12 years, with an average age of $4.5 \pm 1.9$ years. A comparison of differences in age and gender among the three groups revealed no significant difference.

The study was approved by the Ethis Committee of Xuzhou Children's Hospital, Xuzhou, China. Written patient consent was obtained from each patient.

Analysis of the relative expression amount of $m R N A$ of $M R P I$ and MRP2 using RT-PCR. To conduct the reverse transcription reaction, total RNA was extracted from the peripheral blood mononuclear cells using the Total RNA Extraction Kit (Takara, Dalian, China) to synthesize cDNA. The total volume of the PCR reaction was $25 \mu 1$, including $12.5 \mu 1$ of premix type mixed solution, $1 \mu \mathrm{l}$ of forward primer, $1 \mu \mathrm{l}$ of downstream primer, $5.0 \mu \mathrm{l}$ of reverse transcription product, and $5.5 \mu \mathrm{l}$ of double distilled water. The primers used were: MRP1 upstream, 5'-GAGGAACCATATTACAGGTCCGT-3' and downstream, 5'-AGGGGATCATCGAAGAGGTAAAT-3', with a product of $188 \mathrm{bp}$; MRP2 upstream, 5'-AATAGCACC GACTATCCAGCAT-3' and downstream, 5'-GTGAGAGTA GATTGGGGACCTG-3', with a product of $456 \mathrm{bp}$; reference of $\beta$-actin upstream, 5'-CTTAGTTGCGTTACACCCTTTC-3' and downstream, 5'-GGTCACCTTCACCGTTCCAGT-3', product of $526 \mathrm{bp}$. The PCR reaction conditions for MRP1 were: $94^{\circ} \mathrm{C}$ for $3 \mathrm{~min}$, followed by 33 cycles of $94^{\circ} \mathrm{C}$ for $30 \mathrm{sec}$, $55^{\circ} \mathrm{C}$ for $30 \mathrm{sec}, 72^{\circ} \mathrm{C}$ for $1 \mathrm{~min}$, and, $72^{\circ} \mathrm{C}$ for $5 \mathrm{~min}$. The PCR reaction conditions for $\mathrm{MRP} 2$ were: $95^{\circ} \mathrm{C}$ for $2 \mathrm{~min}$, followed by 35 cycles of $95^{\circ} \mathrm{C}$ for $30 \mathrm{sec}, 56^{\circ} \mathrm{C}$ for $30 \mathrm{sec}, 72^{\circ} \mathrm{C}$ for $1 \mathrm{~min}$ and, $72^{\circ} \mathrm{C}$ for $5 \mathrm{~min}$. The relative expression amount of MRP1 and MRP2 was expressed with the corresponding amplified products and gray level ratio of $\beta$-actin.

Analysis of the relative amount of MRP1 and MRP2 protein expression using western blot analysis. The amount of the total protein extracted from the single nuclear membrane was measured using the bicinchoninic acid assay (Beyotime, Beijing, China). The amount of protein in the samples was balanced and run on sodium dodecyl sulfate-polyacrylamide gel electrophoresis (SDS-PAGE; Beyotime). The proteins were then transferred to PVDF membranes (Sigma, St. Louis, MO, USA) using the wet transfer method for $3 \mathrm{~h}$, after which the membranes were incubated with diluted primary antibodies (MRP1, Cat. no. sc-365635, mouse monoclonal, 1:50; Santa Cruz Biotechnology, Inc., Santa Cruz, CA, USA; MRP2, Cat. no. ab3373, mouse monoclonal, 1:100, Abcam, Cambridge, MA, USA), and incubated overnight at $4^{\circ} \mathrm{C}$. The following day, the membranes were rewarmed for $30 \mathrm{~min}$, and washed with buffer solution (Beyotime) for $5 \mathrm{~min} x 3$ times. The membranes were then incubated with diluted secondary antibody (goat anti-mouse antibody 1:1,000; LI-COR Biosciences, Lincoln, NE, USA) and incubated at room temperature for $2 \mathrm{~h}$. The blots were developed after chemical staining and the gel image processing system was used to analyze the molecular weight and net optical density value of the target band. The optical density ratio of the target band/ $\beta$-actin band yielded the relative expression amount of the target protein band.

Statistical analysis. The results were presented as mean \pm SD. The SPSS 16.0 statistical software was applied to compare the expression of MRP2 genes and proteins in all the groups. The ANOVA test was applied to make comparisons between the groups, and the LSD test was applied to make comparisons between any two groups, $\mathrm{P}<0.05$ was considered to indicate statistically significant results.

\section{Results}

Expression of $m R N A$ of $M R P 1$ and $M R P 2$. The relative expression amount of mRNA of MRP1 and MRP2 in the IE group 
Table II. Expression of MRP1 and MRP2 in peripheral blood mononuclear cells of children with intractable epilepsy (mean \pm SD).

\begin{tabular}{|c|c|c|c|}
\hline Group & Cases & MRP1 & MRP2 \\
\hline Group of healthy children without epilepsy & 50 & $1.093 \pm 0.023$ & $1.045 \pm 0.018$ \\
\hline Group of children with epilepsy controlled by anti-epileptic drugs & 50 & $1.131 \pm 0.042^{\mathrm{a}}$ & $1.086 \pm 0.027^{\mathrm{a}}$ \\
\hline Group of intractable epilepsy & 50 & $2.027 \pm 0.034^{\mathrm{b}}$ & $1.902 \pm 0.021^{\mathrm{b}}$ \\
\hline F-value & & 20.391 & 24.197 \\
\hline P-value & & $<0.001$ & $<0.001$ \\
\hline
\end{tabular}

${ }^{\text {aP }}<0.001$ when the group of children with intractable epilepsy was compared to the group of children with epilepsy controlled by anti-epileptic drugs and the group of healthy children without epilepsy. ${ }^{b} \mathrm{P}>0.05$ when the group of children with epilepsy controlled by anti-epileptic drugs was compared to the group of healthy children without epilepsy. MRP, multidrug-resistant associated protein.

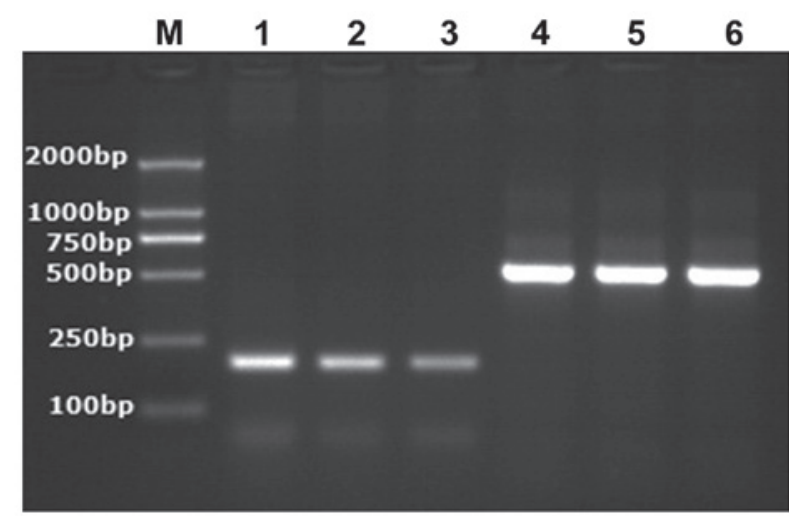

Figure 1. The electropherogram of the mRNA product of multidrug-resistant associated protein 1 in peripheral blood mononuclear cells of children with intractable epilepsy; M, marker; Lanes: 1, group of intractable epilepsy; 2, group of children with epilepsy controlled by anti-epileptic drugs; 3 , group of healthy children without epilepsy; 4-6, internal reference of $\beta$-actin.

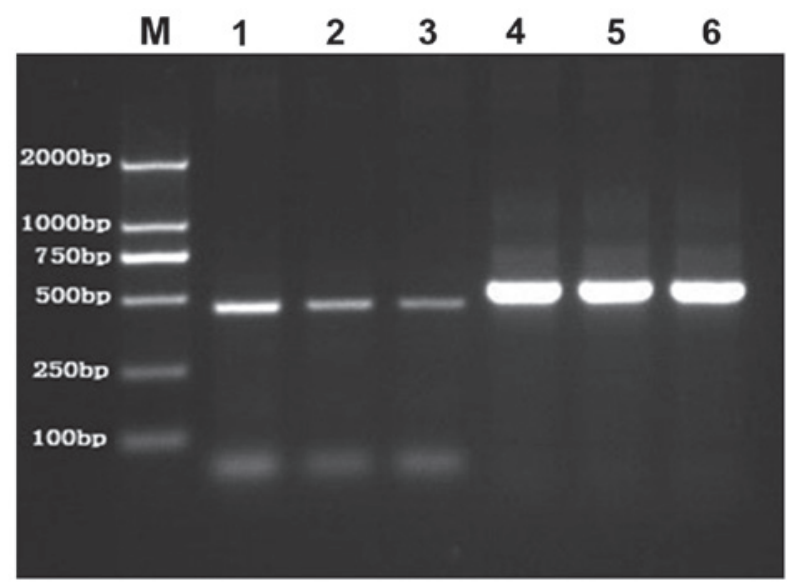

Figure 2. The electropherogram of the mRNA product of multidrug-resistant associated protein 2 in peripheral blood mononuclear cells of children with intractable epilepsy. M, marker; Lanes: 1, group of intractable epilepsy; 2, group of children with epilepsy controlled by anti-epileptic drugs; 3 , group of healthy children without epilepsy; 4-6, internal reference of $\beta$-actin.

increased compared to the AEDs group and the group comprising healthy children without epilepsy. The difference was statistically significant $(\mathrm{P}<0.001)$. However, the relative expression of mRNA of MRP1 and MRP2 in the AEDs group

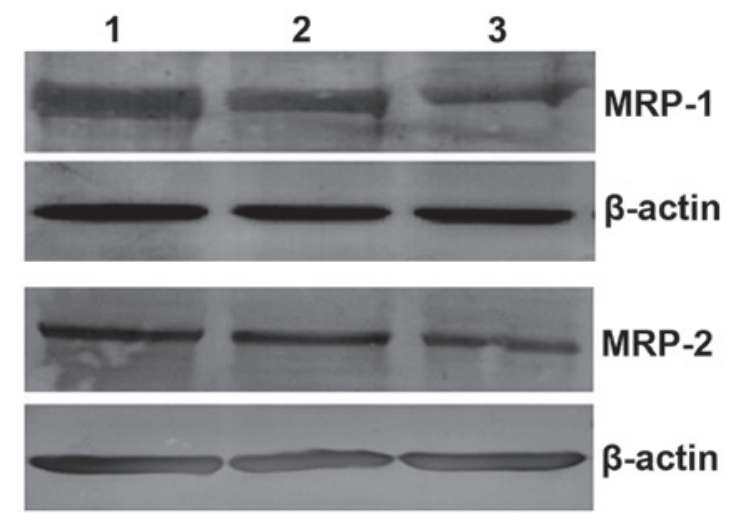

Figure 3. The electropherogram derived from the western blot analysis of multidrug-resistant associated protein 1 and 2 in peripheral blood mononuclear cells of children with intractable epilepsy. Lanes: 1, group of intractable epilepsy; 2, group of children with epilepsy controlled by anti-epileptic drugs; 3 , group of healthy children without epilepsy.

compared to the group of healthy children without epilepsy was not statistically significant ( $\mathrm{P}>0.05)$ (Table I and Figs. 1 and 2).

Relative expression amount of protein of MRP1 and MRP2. The relative expression of proteins MRP1 and MRP2 in the IE group increased compared to AEDs group and the group of healthy children without epilepsy. The difference was statistically significant $(\mathrm{P}<0.001)$. However, a comparison of the relative expression amount of proteins MRP1 and MRP2 in the AEDs group with that in the group of healthy children without epilepsy indicated no statistically significant difference $(\mathrm{P}>0.05)$ (Table II and Fig. 3).

\section{Discussion}

The mechanism of resistance for intractable epilepsy remains to be elucidated. Findings of recent studies have shown that overexpression of the multidrug transporter may be one of the factors for this resistance (11-13). MRP is an important multidrug transporter that is involved in adjusting the density of antiepileptic drugs within and beyond the cells of epileptic individuals $(14,15)$.

Although significant progress has been revealed in MRP structure and function studies, the majority of these mainly focus on tumors and blood diseases $(16,17)$. Investigations into 
the expression of MRP are relatively few and limited to animal epileptic models or in vitro adult brain tissue samples (18-20), which restricts the progress of studies due to difficulty in sampling brain tissues and repeating, as well as small sample size. However, collection from peripheral blood is simple and convenient, and may support dynamic observation. In addition to brain tissues, the expression of MRP also exists in the respiratory tract, digestive tract, urinary tract, and peripheral blood (8,21). Antiepileptic drugs initially enter the bloodstream and then the brain tissues through blood brain barrier. The concentration of drugs with pharmacological effects are similar to the free concentration in blood. Thus, MRP may be induced to overexpress simultaneously inside the blood and brain.

The expression of mRNA of MRP increased significantly in the peripheral blood of recurrent acute leukemic patients and MDR-TB patients $(9,22)$ which indicated that a high expression of MRP in peripheral blood was closely associated with the recurrence of leukemia and multidrug resistance of tuberculosis. In addition, it has been identified that the expression of MDR genes and MRP1 mRNA in the peripheral blood of IE adult patients was significantly higher than that of the group controlled by anti-epileptic drugs and the healthy control group, which indicated that MDR1 and MRP1 may be associated with the tolerance of epilepsy $(23,24)$. However, the number of studies focusing on MRP expression in peripheral blood of epileptic children, especially IE children, are limited. Thus, in the present study, we concentrated on examining the expression of the MRP gene and protein in peripheral blood mononuclear cells of IE children, to discuss the role of MRP in the pathogenesis of IE children. The result showed that MRP1 and MRP2 was expressed in the peripheral blood mononuclear cells of, not only IE children, but also the AEDs children and the healthy children without epilepsy $(25,26)$. Compared to the AEDs and the children without epilepsy, a higher mRNA and protein expression of MRP1 and MRP2 for IE children was observed, and the difference was statistically significant. By contrast, no difference was identified between the AEDs group and the healthy control group (27). The results indicate that MRP1 and MRP2 was distributed extensively in the peripheral blood of the different groups. Of note, single drug induction did not cause the increase of MRP1 and MRP2 in peripheral blood, thus, MRP1 and MRP2 may be involved in the resistance process of the IE group. This result was consistent with the findings of Lan et al following an investigation of the MRP1 in the peripheral blood of adult IE patients (28).

Repeated abnormal discharges of the neurons in the brain and epileptic seizures are considered the major induction factor of a high MRP expression. For example, studies on rat in the status epilepticus have shown that the expression of MRP1 and MRP2 in neurons in the hippocampus and surrounding cortex (29), vascular endothelial cells as well as astrocyte increased significantly. The long-term intervention treatment of certain anti-epileptic drugs, such as oxcarbazepine, may also induce the expression of MRP1 in rat (30). However, investigations into tuberous sclerosis identified that the expression of MRPs in certain patients already existed prior to the treatment of anti-epileptic drugs (31).

The results of the present study have shown that the application of anti-epileptic drugs failed to increase MRP1 and MRP2 in the peripheral blood of the AEDs. This finding indicates that besides the effects of repeated epileptic seizure and anti-epileptic drugs, elevation of MRP may also be the result of multiple factors and mechanisms, such as the types and acting time of the influential factors, including genetics and immunity. Additionally, the polymorphism and haplotype of MRP genes may affect the reactions of epileptics towards anti-epileptic drugs, thereby resulting in IE. Therefore, the exact mechanism of MRP in IE tolerance requires intensive and extensive investigations.

\section{References}

1. Sugano $\mathrm{H}$ and Arai $\mathrm{H}$ : Epilepsy surgery for pediatric epilepsy: Optimal timing of surgical intervention. Neurol Med Chir (Tokyo) 55: 399-406, 2015.

2. Epilepsy: Benefits and risks of reoperation after failed surgery for intractable epilepsy. Nat Rev Neurol 11: 247, 2015.

3. Sebe JY and Baraban SC: The promise of an interneuron-based cell therapy for epilepsy. Dev Neurobiol 71: 107-117, 2011.

4. Jose M and Thomas SV: Role of multidrug transporters in neurotherapeutics. Ann Indian Acad Neurol 12: 89-98, 2009.

5. Xu J, Deng Y and Gao B: Blood-CSF barrier related translocator and intractable epilepsy. J Appl Clin Pediatr 27: 1900-1902, 2012.

6. Luna-Tortós C, Fedrowitz M and Löscher W: Evaluation of transport of common antiepileptic drugs by human multidrug resistance-associated proteins (MRP1, 2 and 5) that are overexpressed in pharmacoresistant epilepsy. Neuropharmacology 58 : 1019-1032, 2010.

7. Marquez B and Van Bambeke F: ABC multidrug transporters: target for modulation of drug pharmacokinetics and drug-drug interactions. Curr Drug Targets 12: 600-620, 2011.

8. Schinkel AH and Jonker JW: Mammalian drug efflux transporters of the ATP binding cassette (ABC) family: An overview. Adv Drug Deliv Rev 55: 3-29, 2003.

9. Keppler D: Multidrug resistance proteins (MRPs, ABCCs): Importance for pathophysiology and drug therapy. Handbook Exp Pharmacol 201: 299-323, 2011.

10. Kwan P, Arzimanoglou A, Berg AT, Brodie MJ, Allen Hauser W, Mathern G, Moshé SL, Perucca E, Wiebe S and French J: Definition of drug resistant epilepsy: Consensus proposal by the ad hoc Task Force of the ILAE Commission on Therapeutic Strategies. Epilepsia 51: 1069-1077, 2010.

11. Rong H, Jin L, Wei W, Wang X and Xi Z: Alpha-synuclein is a potential biomarker in the serum and CSF of patients with intractable epilepsy. Seizure 27: 6-9, 2015.

12. Grote A, Witt JA, Surges R, von Lehe M, Pieper M, Elger CE, Helmstaedter C, Ormond DR, Schramm J and Delev D: A second chance-reoperation in patients with failed surgery for intractable epilepsy: long-term outcome, neuropsychology and complications. J Neurol Neurosurg Psychiatry: pii: jnnp-2015-310322, 2015.

13. Fernandez L, Gedela S, Tamber M and Sogawa Y: Vagus nerve stimulation in children less than 3 years with medically intractable epilepsy. Epilepsy Res 112: 37-42, 2015.

14. Yi JH, Cho YJ, Kim WJ, Lee MG and Lee JH: Genetic variations of ABCC2 gene associated with adverse drug reactions to valproic acid in Korean epileptic patients. Genomics Inform 11: 254-262, 2013.

15. Chen YH, Wang CC, Xiao X, Wei L and Xu G: Multidrug resistance-associated protein 1 decreases the concentrations of antiepileptic drugs in cortical extracellular fluid in amygdale kindling rats. Acta Pharmacol Sin 34: 473-479, 2013.

16. Xu Y, Wang L, Zheng X, Liu G, Wang Y, Lai X and Li J: Positive expression of p53, c-erbB2 and MRP proteins is correlated with survival rates of NSCLC patients. Mol Clin Oncol 1: 487-492, 2013.

17. Kovalev AA, Tsvetaeva DA and Grudinskaja TV: Role of ABC-cassette transporters (MDR1, MRP1, BCRP) in the development of primary and acquired multiple drug resistance in patients with early and metastatic breast cancer. Exp Oncol 35: 287-290, 2013.

18. Nasilowska-Adamska B, Solarska I, Paluszewska M, Malinowska I, Jedrzejczak WW and Warzocha K: FLT3-ITD and MLL-PTD influence the expression of MDR-1, MRP-1, and BCRP mRNA but not LRP mRNA assessed with RQ-PCR method in adult acute myeloid leukemia. Ann Hematol 93: 577-593, 2014. 
19. Calatozzolo C, Pollo B, Botturi A, Dinapoli L, Carosi M, Salmaggi A and Maschio M: Multidrug resistance proteins expression in glioma patients with epilepsy. J Neurooncol 110: 129-135, 2012.

20. Yao D, Liu L, Jin S, Li J and Liu XD: Overexpression of multidrug resistance-associated protein 2 in the brain of pentylenetetrazolekindled rats. Neuroscience 227: 283-292, 2012.

21. Zhang Y, Dai Y, Rui L, et al: Effect of Oxcarbazepine on multidrug resistance associated protein 1 expression in hippocampus of kainic acid-induced seizure in rats during development period rats. Chin J Appl Clin 28: 1170-1171, 2013.

22. Zhan L, Ping W and Jing Z: The expression of multi-drug resistance transmembrane transporter in the peripheral blood of patients with multi-drug resistant tuberculosis. Zhonghua Jie He He Hu Xi Za Zhi 34: 520-522, 2011 (In Chinese).

23. Song Y, Bing L and Zhong L: Expression of multi-drug resistance-associated protein genein acute leukemia. Acta Acad Med Qingdao Univ 37: 41-43, 2001.

24. Ban JJ, Jung KH, Chu K, Lee ST, Jeon D, Park KI, Moon HJ, Kim H, Kim S, Lee SK, et al: Profiles of multidrug resistance protein-1 in the peripheral blood mononuclear cells of patients with refractory epilepsy. PLoS One 7: e36985, 2012.

25. Murakami N, Morioka T, Hashiguchi K, Suzuki SO, Shigeto H, Sakata A and Sasaki T: Clinical and histological characteristics of ictal onset zone in cases of intractable epilepsy associated with dysembryoplastic neuroepithelial tumor. Brain Nerve 67: 525-532, 2015 (In Japanese).
26. Mateo-Carrasco H, Serrano-Castro PJ, Molina-Cuadrado E, Goodwin M, Nguyen TV and Kotecha PN: Role of high-dose levetiracetam as add-on therapy for intractable epilepsy: Case report and brief review of the literature. Int J Clin Pharm 37: $559-562,2015$.

27. Meador KJ, Kapur R, Loring DW, Kanner AM and Morrell MJ; RNS $^{\circledR}$ System Pivotal Trial Investigators: Quality of life and mood in patients with medically intractable epilepsy treated with targeted responsive neurostimulation. Epilepsy Behav 45: 242-247, 2015.

28. Lan T, Teng M, Song J, et al: The expression of multidrug resistance protein-1 in peripheral blood of patients with intractable epilepsy. Zhonghua Jie He He Hu Xi Za Zhi 39: 403-404, 2006 (In Chinese).

29. van Vliet EA, Redeker S, Aronica E, Edelbroek PM and Gorter JA: Expression of multidrug transporters MRP1, MRP2, and BCRP shortly after status epilepticus, during the latent period, and in chronic epileptic rats. Epilepsia 46: 1569-1580, 2005.

30. Lazarowski A, Lubieniecki F, Camarero S, Pomata H, Bartuluchi M, Sevlever G and Taratuto AL: Multidrug resistance proteins in tuberous sclerosis and refractory epilepsy. Pediatr Neurol 30: 102-106, 2004.

31. Qu J, Zhou BT, Yin JY, Xu XJ, Zhao YC, Lei GH, Tang Q, Zhou HH and Liu ZQ: ABCC2 polymorphisms and haplotype are associated with drug resistance in Chinese epileptic patients. CNS Neurosci Ther 18: 647-651, 2012. 